\title{
Nemaline Myopathy in an Adult with Primary Hypothyroidism
}

\author{
Marcelino G. Reyes, Alexander Tal, David Abrahamson and Maurice Schwartz
}

\begin{abstract}
We report a 50 year old woman with primary hypothyroidism and nemaline myopathy to call attention to the rare coexistence of these two disorders.

RÉSUMÉ: Myopathie nemaline chez un adulte souffrant d'hypothyroidie primaire Nous reportons le cas d'une femme de 50 ans souffrant d'hypothyroidie primaire et myopathie "nemaline" pour souligner la rare coexistence de ces deux entites.
\end{abstract}

Can. J. Neurol. Sci. 1986; 13:117-119

In this report, we present a patient with primary hypothyroidism and muscle biopsy findings of nemaline myopathy.

\section{CASE Report}

A 50 year old black woman was admitted to our hospital on March 29. 1984. She had been taking alpha methyldopa for the treatment of hypertension since age 47 and had felt well until a year prior to admission when she began to have exertional dyspnea and swelling of her ankles. Three months before admission, she began to experience generalized weakness. Her dyspnea progressively worsened during the two weeks before admission. Examination revealed jugular venous distension, fine crackles in both lung fields, cardiomegaly with a soft $\mathrm{S} 3$ gallop and a grade $2 / 6$ blowing apical systolic murmur radiating to the left axilla, enlarged liver and marked pedal edema. Her thyroid gland was not palpable. Vital signs were: $140 / 80 \mathrm{~mm} \mathrm{Hg}$, pulse regular at 80 beats per minute, respiration 24 per minute and temperature $36.9^{\circ} \mathrm{C}$. Neurological examination revealed symmetrical, slight weakness of the muscles of the pelvic and shoulder girdles. The relaxation phase of muscle stretch reflexes appeared prolonged. She was alert but spoke slowly in a low-pitched voice. Radiographs of the chest showed marked cardiomegaly with signs of pericardial effusion and right pleural effusion. Electrocardiograms revealed left anterior hemiblock, non-specific $T$ wave abnormalities and low voltage in the limb leads. M-mode and 2 dimensional echocardiograms confirmed the large pericardial effusion but showed normal myocardial contractility and size of the chambers and valves. She was started on digoxin $0.25 \mathrm{mg} /$ day and furosemide. Tests of thyroid function on March 29, 1984 are shown in the Table. No antibodies were detected against thyroglobulins or thyroid microsomes. A diagnosis of primary hypothyroidism was made and she was treated with $\mathrm{L}$ thyroxine (starting dose of $0.05 \mathrm{mg} / \mathrm{day}$ which was increased to $0.075 \mathrm{mg} /$ day in three weeks) and digoxin was stopped. On April 30, 1984 her congestive heart failure had improved but her pericardial effusion had not and her proximal weakness was only questionably better. Thyroid function tests (Table) had improved. She was discharged home from the hospital on April 30, 1984.

She was readmitted to the hospital nine days later because of worsening of her congestive heart failure. She was again given digoxin and the dose of $L$ thyroxine was increased to $0.1 \mathrm{mg} /$ day but her congestive heart failure did not improve. On May 11, 1984, a partial pericardiectomy was done through a left anterior thoracotomy. The pericardium was slightly thickened but the inner surface was smooth and shiny. Approximately one liter of straw colored fluid was removed which was negative for bacterial, acid fast and fungal cultures. Histologic examination of the pericardium showed fibrosis and chronic inflammation. Her congestive heart failure improved but again got worse twelve days after surgery. On May 23, 1984 an echocardiogram showed reaccumulation of the pericardial effusion. Decreased right ventricular compliance. increased end diastolic pressure and normal pulmonary wedge pressure were found on cardiac catheterization. A right thoractomy for lysis of pleural adhesions and partial pericardiectomy was done on May 25. 1984. Again, a modest improvement of her congestive heart failure was observed.

\begin{tabular}{llll}
\hline \multicolumn{4}{l}{ Table: Summary of Thyroid Function Tests } \\
\hline Test & $\mathbf{3 / 2 9 / 8 4}$ & $\mathbf{4 / 2 5 / 8 4}$ & $\mathbf{5 / 2 9 / 8 4}$ \\
\hline $\mathrm{T}_{4}(\mathrm{NL} \mathrm{5}-12 \mathrm{ug} / \mathrm{dl})$ & $2 \mathrm{ug} / \mathrm{dl}$ & $2.7 \mathrm{ug} / \mathrm{dl}$ & \\
$\mathrm{T}_{3}$ RU (NL 30-40\%) & $34 \%$ & $38 \%$ & \\
FTI (NL 1.5-4.8) & 0.7 & 1.0 & \\
TSH (NL 0.4-4.8 ulU/ml) & $30.6 \mathrm{u} \mathrm{IU} / \mathrm{ml}$ & $10.8 \mathrm{ulU} / \mathrm{ml}$ & $<\mathrm{lulU} / \mathrm{ml}$
\end{tabular}

$\mathrm{T}_{4}$ Total thyroxine

$T_{3} R U$ Tri-iodothyronine resin uptake

FTI Free Thyroxine Index

TSH Thyroid Stimulating Hormone 
Although her serum TSH on May 29, 1984 indicated a euthyroid state (Table), her muscle weakness persisted. Serum creatine kinase, lactic dehydrogenase and aldolase were normal, but immunologic tests revealed a titer of antinuclear antibodies of 1:2560 with homogenous pattern. anti-ribonucleoprotein of $1: 4$ and antideoxyribonucleic acid of less than 1:10. $\mathrm{C} 3$ and $\mathrm{C} 4$ fractions of complement were normal but $\mathrm{C}_{14}$ binding of $42 \%$ (NL 0-13) and Raji immune complex assay of $6900 \mathrm{mcg}$ antihuman globulin eq/ml (NL $0-12)$ were elevated. There were no antibodies against smooth muscle and the rheumatoid factor test was negative. Serum protein electrophoresis showed low albumin $2.7 \mathrm{gm} / \mathrm{dl}$ (NL 3.5-4.7) and elevated globulins. Immunoglobulin studies showed IgG $3741 \mathrm{mg} / \mathrm{dl}$ (NL 70-1700), IgA $987 \mathrm{mg} / \mathrm{dl}$ (NL 70-350) and IgM $245 \mathrm{mg} / \mathrm{dl}$ (NL 70-210). Electromyograms of the hypothenar muscles showed non-specific low amplitude potentials. Motor nerve conduction velocity of the left ulnar nerve was slightly slow at $52 \mathrm{~m} / \mathrm{s}$. Sensory conduction of the left ulnar and median nerves were slow at 38 and $39 \mathrm{~m} / \mathrm{s}$. Repetitive stimulation of the ulnar nerve at 2,5 and $20 \mathrm{~Hz}$ the wrist revealed no incremental or decremental response of the abductor digiti minimi. Biopsy of the right deltoid muscle on June 12, 1984 showed nemaline rods in many fibers (Figure 1), predominance in the number of type 1 fibers with a few scattered atrophic type 2 fibers (Figure 2) and rare atrophic type 1 fibers. Percent of fibers with nemaline rods were estimated from seven high power fields in the modified trichrome stained sections. Nemaline rods were found in $32 \pm 7.6-57,35$ percent (given as mean + std err, range and median) of 126 fibers counted from seven fields. In the myosin adenosine triphosphatase $(\mathrm{pH} 9.4)$ stained sections, the percent of type 1 fibers were estimated as $87 \pm$ $3,71-100,86$ of 189 fibers from nine fields. Electron microscopic examination showed nemaline rods among the myofibrils (Figure 3 ). Some appeared to arise from " $Z$ " discs and the " $Z$ " discs themselves appeared thickened and some showed streaming. There were no rods in the nuclei of the myofibers. Fluorescein-labeled anti-lgG, $\mathrm{C}_{\mathrm{Iq}_{\mathrm{a}}}$ and fibrinogen antibodies were deposited along sarcolemmal membranes of a few muscle fibers but not in their cytoplasm or nemaline rods.

One week after her muscle biopsy she developed sepsis and respiratory failure. She died 10 days later. Her family refused permission for an autopsy examination.

\section{COMMENTS}

Our patient showed characteristic laboratory findings of primary hypothyroidism with pericardial effusion'. Her muscle biopsy findings of nemaline rods and a predominance in the number of type I fibers were, however, characteristic of nemaline myopathy. ${ }^{2.3}$ Rare nemaline rods have been reported in a few patients with hypothyroid myopathy, ${ }^{4.5}$ but most hypothyroid patients do not have nemaline rods in their skeletal muscle. ${ }^{3,6}$ A predominance in the number of type I fibers has been reported in some patients with hypothyroid myopathy, ${ }^{6}$ but again, most patients do not show this finding. ${ }^{3}$ Because of the abundance of nemaline rods in her muscle biopsy and the recent onset of her weakness, we believe that she had the adult or "late-onset" nemaline myopathy instead of the congenital or "early-onset" nemaline myopathy or hypothyroid myopathy with "accompanying rods". ${ }^{2}$ Her lack of response to thyroid treatment also argues for nemaline rather than hypothyroid myopathy. A few "accompanying rods", often in degenerating muscle fibers, have also been reported in some patients with polymyositis, but we do not think that our patient had polymyositis. Moreover, unexplained abnormalities in serum immunoglobulins not unlike our patient's have been reported in adult nemaline myopathy. ${ }^{2}$

Although we believe that the coexistence of primary hypothyroidism and adult nemaline myopathy was fortuitous in our patient we cannot rule out the possibility that alterations of muscle contractility and/or thyroid hormones in primary hypothyroidism could explain her muscle biopsy findings. Rods form in tenotomized muscle with intact nerve supply in the rat,

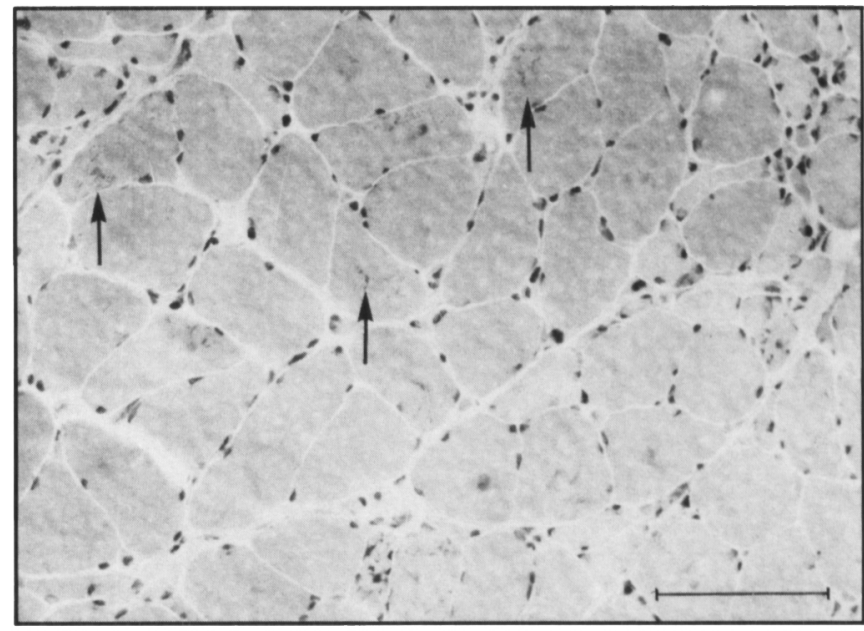

Figure 1-Modified trichrome stained frozen sections showing nemaline rods in the central and paracentral regions of muscle fibers. Arrows highlight the nemaline rods in three of the fibers. Bar $=100 \mu \mathrm{m}$.

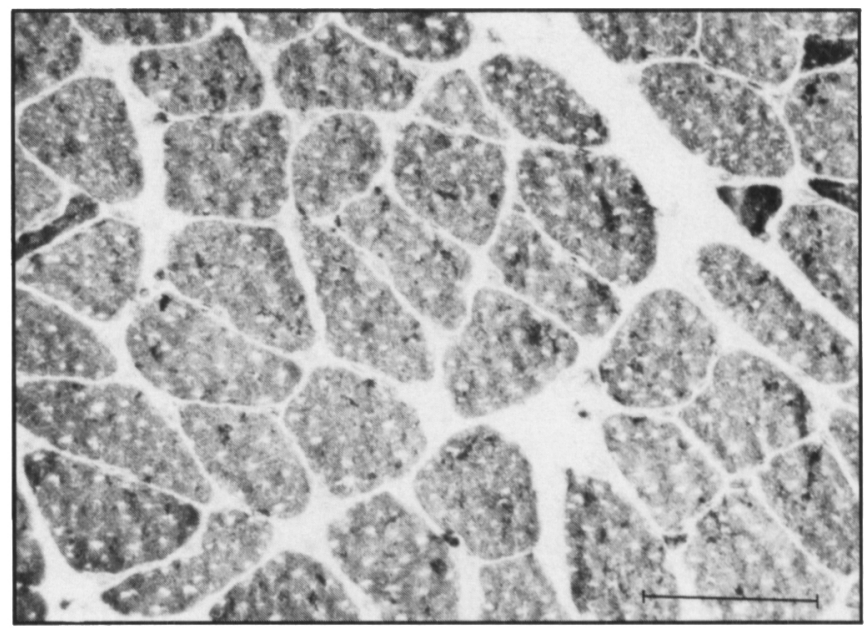

Figure 2 - Myosin adenosine triphosphatase ( $\mathrm{pH}$ 9.4) stained sections of same muscle showing predominance in the number of type l fibers. Darkly stained type 2 fibers are atrophic. Bar $=100 \mu \mathrm{m}$.

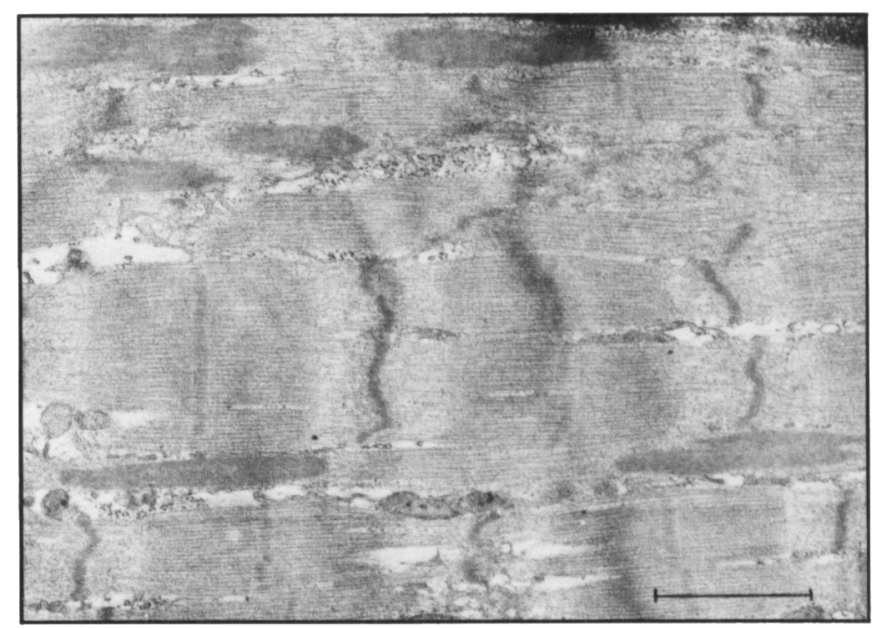

Figure 3 - Electronmicrograph showing nemaline several nemaline rods in the vicinity of ' $Z$ ' discs and between myofibrils. Bar $=I \mu \mathrm{m}$. 
presumably because of an altered contractility of skeletal muscle. ${ }^{7}$ Also, a deficiency of thyroxine caused by thyroidectomy in the rat transforms type 2 fibers into type 1 fibers and causes the synthesis of a new protein in skeletal muscles. ${ }^{8}$ Lastly, thyroid stimulating hormone (TSH) by speeding up the conversion of thyrotrophin releasing hormone (TRH) to one of its more active metabolites-histidyl-proline-diketoepiperazine (His-Pro-DKP) can conceivably deplete TRH in lower motor neurons ${ }^{9}$ and cause rods to form in skeletal muscle through loss of trophic influence of the lower motor neuron similar to that proposed by Engel in the congenital nemaline myopathy. ${ }^{2}$ We should point out, however, that we have no proof that any of these findings apply to our patient. Moreover, the predominance of the number of type 1 fibers in hypothyroid myopathy is thought to be the result of atrophy and loss of type 2 fibers ${ }^{6}$ rather than from a transformation of type 2 fibers to type 1 fibers. Similarly, nemaline rods are made up primarily of alpha-actinin ${ }^{10}$ which differs from the novel protein synthesized by skeletal muscle in thyroidectomized rats. ${ }^{8}$

Nemaline rods in the myocardium has been reported as a cause of congestive heart failure in an adult with nemaline myopathy. " Because we did not biopsy her myocardium we can not tell if nemaline cardiomyopathy may have contributed to our patient's congestive heart failure.

\section{ACKNOWLEDGEMENTS}

This work was supported in part by grants from the Mount Sinai Research Foundation, the Edward Weinstein Foundation and the Evelyn Steinberg Cancer Research Foundation.

\section{REFERENCES}

1. DeGroot LJ, Larsen PR. Refetoff S. Stanbury JB. The thyroid and its diseases. John Wiley and Sons. New York. Fifth Ed. 1984.

2. Engel WK. Rod (nemaline) disease. In Goldensohn ES. Appel SH. Eds. Scientific approaches to clinical neurology. Lea and Febiger. Philadelphia, 1977: Vol 2: 1668-1691.

3. Carpenter S, Karpati G. Pathology of skeletal muscle. Churchill Livingstone Ltd. Philadelphia, 1984.

4. Afifi AK, Najiar SS, Mire-Salman JM. Bergman RA. The myopathology of the Kocher-Debré-Sémélaigne syndrome. J Neurol Sci 1974: 22: 445-470.

5. Godet-Guillain J, Fardeau M. Hypothyroid myopathy. Histological and ultrastructural study of an atrophic form. In Walton JN. Canal N, Scarlatto G, Eds. Muscle Diseases. Excerpta Medica. Amsterdam, 1970; 512-515.

6. McKeran RO, Slavin G. Andrews TM, Ward P. Mair WGP. Muscle fiber type changes in hypothyroid myopathy. J Clin Pathol 1975: 28: $659-653$.

7. Karpati G, Carpenter S, Eisen AA. Experimental core-like lesions and nemaline rods. Arch Neurol 1972: 27: 237-251.

8. Gagnon J, Ho-Kim MA, Champagne C. Tremblay RR, Rogers PA. Modulation of a major 30-kDa skeletal muscle protein by thyroid hormone. FEBS Lett 1985; 180: 335-340.

9. Jackson IMD. Thyrotropin-releasing hormone. New Eng J Med. 1982; 306: 145-155.

10. Jennekens, FGI, Roord JJ, Veldman H, Willemse J, Jockusch BM. Congenital nemaline myopathy. 1. Defective organization of alpha restricted to muscle. Musc Nerve 1983; 6: 61-68.

11. Meier C, Voellmy W. Gertsch M. Zimmermann A. Geissbuhler J. Nemaline myopathy appearing in adults as cardiomyopathy. Arch Neurol 1984: 41: 443-445. 